\title{
Agricultura familiar como portadora de inovações no desenvolvimento sustentável na região centro oeste
}

\section{Family agriculture as a carrier of innovations in sustainable development in the central western region}

DOI: $10.46814 / 1 a j d v 3 n 4-072$

Recebimento dos originais: 01/05/2021

Aceitação para publicação: 31/06/2021

\section{Elizabete Maria da Silva}

Doutora em Ciências Ambientais e Sustentabilidade Agropecuária

Universidade Federal Rural da Amazônia, UFRA Rod. PA 275 s/n, km13, Zona Rural, Parauapebas, Pará

dasilvabete@yahoo.com.br

\section{Cleonice Le bourlegat}

Doutora em Geografia

Mestrado e Doutorado em Desenvolvimento Local, Universidade Católica om Bosco, UCDB.

Avenida Tamandaré, 6000, Jardim Seminário, Campo Grande, MS

le-bourlegat@uol.com.br

\section{Antonia Railda Roel}

Doutorado em Entomologia

Mestrado e Doutorado em Ciências Ambientais e Sustentabilidade Agropecuária, Universidade

Católica om Bosco, UCDB.

Avenida Tamandaré, 6000, Jardim Seminário, Campo Grande, MS

arroel@ucdb.br

\section{RESUMO}

Agricultura familiar na região Centro Oeste tem sido palco de inovações agrícolas no país, que se pautam nas práticas imbricadas da econômica solidária e da produção agroecológica, por meio da mobilização de recursos reciprocitários.

Palavras-chave: agricultura familiar, economia solidária, agroecologia

\section{ABSTRACT}

Family farming in the Midwest region has been the scene of agricultural innovations in the country, which are based on overlapping practices of economic solidarity and agro ecological production, through the mobilization of the reciprocal resource.

Keywords: family farming, solidarity economy agroecology 


\section{INTRODUÇÃO}

A agricultura familiar é importante para o Brasil, fator evidenciado nos censos agropecuários desde 1950, onde os agricultores familiares que têm menos de 100 hectares sempre estiveram em torno de $90 \%$ do total de estabelecimentos, com $20 \%$ da área ocupada (Veiga et al., 2001). Apesar disso, as dificuldades, para os que dela vivem, tem se agravado nos últimos anos, principalmente pela falta de perspectiva causada pelos altos custos para produzir, incluindo tempo, força física e a desvalorização do produto agrícola, apesar de todo o incentivo para a permanencia do agricultor no campo (Navarros e Campos, 2013, p. 14).

Políticas públicas para o setor agrícola familiar brasileiro, muitas vezes são formuladas e forma exógena, sem considerar a participação dos autores locais. Esse fator dificulta o empoderamento local por aqueles que deveriam ser os beneficiários (Rodrigues; Borges; Virginio; Vergnano, 2021).

No entanto, grupos motivados ideologicamente conseguem se unir e organizar a produção, conforme Borges (2012), que afirma que no Brasil os princípios associativos ou coletivos de produção agrária têm sido valorizados como uma alternativa para maior sustentabilidade para esse setor. Tais como os princípios da economia solidária, que tem sido defendida por alguns autores como alternativa para a sustentabilidade, principalmente, da agricultura familiar (Singer, 2002, Lopes; Baldi, 2005, entre outros).

De acordo com Soares (2006), os empreendimentos de economia solidária são grupos fortemente orientados pela ideologia, que como uma alternativa a economia convencional busca favorecer a economia local, fechando o ciclo da produção/consumo/distribuição internamente nas experiências solidárias. Em geral estão organizados por um grupo muito motivado e unido pela mesma visão de mundo. Esses grupos são de pequeno porte, limitados a um território, o que favorece o desenvolvimento local.

A motivação ideológica também é defendida por Caporal e Costabeber (2002) para a adoção de inovações na agricultura, principalmente para uma agricultura multifuncional ou alternativa que é definida pelos autores como ciência agroecológica.

Assim, a região Centro Oeste é apresentada como portadora de inovações, possibilidade de tornar a agricultura familiar mais competitiva e eficiente, por meio da dependência entre produtores, num processo de reciprocidade. Partindo se da hipótese que os grupos organizados de forma extrafamiliares são fortemente motivados ideologicamente na defesa dos princípios da economia solidária, entre esses a produção ecologicamente correta, a partir dos moldes da agroecologia.

\section{METODOLOGIA}


A pesquisa é exploratória e começou a partir de dados secundários, obtidos com uma revisão bibliográfica sobre os assuntos ligados ao tema de cada capítulo da pesquisa. Além da revisão bibliográfica, a pesquisa utilizarou dados primários, a serem obtidos a partir da aplicação de questionários numa pesquisa de campo.

Conforme a revisão de cada capitulo foi sendo esboçada, foi construído um questionário, com os indicadores norteadores da pesquisa.

A aplicação de questionários foi realizada em empreendimentos de economia solidária, com práticas agroecológicas, de agricultores familiares da Região Centro Oeste, envolvidos em diferentes atividades agrícolas familiares, produção, comercialização ou crédito. Esses empreendimentos foram escolhidos entre os de mais tempo de atuação, maior abrangência territorial e participação nos fóruns locais de economia solidária. Foram entrevistados empreendimentos nos Estados de Mato Grosso, Mato Grosso do Sul e Goiás. Também foram entrevistados comerciantes locais, bem como alguns moradores do entorno, visando verificar a incidência desses empreendimentos na promoção do desenvolvimento local das comunidades sedes.

Os questionários foram quali-quantitativos, com a maioria de perguntas fechadas.

\section{RESULTADOS E DISCUSSÃO}

Os resultados atuais são preliminares, pois a pesquisa estava na fase de levantamento de dados, ou seja, os dados secundários, não tendo sido realizada ainda o levantamento dos dados primários, com a aplicação dos questionários.

Assim foi feito um levantamento de empreendimentos com possibilidades de fornecerem as informações necessárias para responder a grande questão da pesquisa: As práticas de economia solidária na agricultura familiar têm sido indutoras de inovações que promovam a sustentabilidade do desenvolvimento na agricultura familiar na região Centro Oeste? Neste particular, chama atenção a prática da agricultura agroecológica que se percebe recorrente nesse segmento agrícola.

Foram levantados dados preliminares de empreendimentos de agricultores familiares na região Cento Oeste, sendo localizados empreendimentos econômicos solidários, com ênfase na produção agroecológica na área das finanças solidárias, comercialização e produção.

$\mathrm{Na}$ área das finanças solidárias foram localizados cinco bancos comunitários de desenvolvimento com atuação diretamente na agricultura familiar. Esses empreendimentos são gestados pela população local, por meio de um conselho gestor. Cada banco possui uma moeda própria, que permite a circulação de mercadorias entre os participantes.

São esses: o Banco ITA, cuja moeda social também é denominada Ita, tem sua sede no assentamento Itamarati, Ponta Porã, MS; o Banco Pantanal, que tem a moeda social de nome 
pantaneira, com sua sede no município de Anastácio, MS; o Banco Cerrado, que tem a moeda social de nome Bacuri, e sua sede é no município de Rondonópolis, MT; o Banco Raiz, cuja moeda social tem o nome de Semente, tem sua sede no município de Alta Floresta, MT; o Banco Pequi, que tem a moeda social denominada também de Pequi, possui sua sede no município de Iporá, GO.

Quanto a comercialização e produção, entre os diversos empreendimentos econômicos solidários de agricultores familiares da Região Centro Oeste, foram escolhidos, provisoriamente, nove empreendimentos e uma entidade de apoio. A cooperativa de produtores rurais de Anastácio (Copran), Município de Anastácio, MS; Cooperativa dos agricultores familiares do Assentamento Itamarati (Cooperafi) e a Cooperativa Agroindustrial Ceres (Coopaceres), ambas com sede no assentamento Itamarati, município de Ponta Porã, MS; Associação Dando as Mãos, município de Rondonópolis, MT; Cooperativa de agricultores varzea-grandenses, município de Várzea Grande, MT; Associação Rural Organizada Para Ajuda Mútua (AJOPAM), município de Juína, MT; Cooperativa Mista dos Agricultores Familiares Economia Solidária e Produção Agroecológica de Rio Verde e Região, município de Rio Verde, GO; Cooperativa dos Produtores Rurais de Iporá (Coopercoisas), município de Iporá, GO; Cooperativa de Produção Agroindustrial Familiar do Sudoeste Goiano (Coopfas), Jatai, GO, e a entidade de apoio Instituto Ouro Verde, com sede no município de Alta Floresta, MT.

Todas as associações, cooperativas e Instituto citados, desenvolvem atividades consideradas inovadoras na agricultura familiar, são gestores de bancos comunitários de desenvolvimentos, sites especificamente para comercialização dos produtos, projetos para beneficiamento da produção, bem como captação de recursos para conscientização e investimentos na produção ecologicamente correta, nos moldes da agroecologia. Ainda mobilizam os produtores na organização da produção para a comercialização no mercado local. Isso a partir da autogestão, com uma participação democrática e divisão das sobras.

\section{CONCLUSÃO}

Portanto, pelo levantamento feito, até o momento da pesquisa, os empreendimentos da economia solidária, de agricultores familiares da Região Centro Oeste, possuíam uma nova forma de organização do trabalho, ou seja, apresentavam uma série de inovações econômicas, sociais e políticas, tanto na produção, quanto na comercialização, consumo e financiamento em diversos aspectos, passando da competição para a cooperação entre agentes. Sendo necessárias maiores averiguações para comprovação ou não da sustentabilidade desses grupos, bem como a interação desses com as políticas públicas direcionadas ao desenvolvimento local. 


\section{REFERÊNCIAS}

Borges, J. L. Movimentos Sociais e Sustentabilidade: os Desafios da "Extensão Rural Agroecológica" em Assentamentos de Reforma Agrária. Revista Cesumar-Ciências Humanas e Sociais Aplicadas, v. 17, n. $1,2012$.

Caporal, F. R. e Costabeber, J. A. Análise multidimensional da sustentabilidade: uma proposta metodológica a partir da agroecologia. Agroecol. e Desenv. Rur. Sustent., Porto Alegre, v.3, n.3, Jul/Set 2002.

Lopes, F. D. e Baldi, Mariana. Laços Sociais e Formação de Arranjos Organizacionais Cooperativos Proposição de um Modelo de Análise. RAC, v. 9, n. 2, Abr./Jun. 2005: 81-101.

Navarro, Z. e Campos, S. K. A "pequena produção rural” no Brasil. Ganhar tempo é possível? Brasília: CGEE, 2013, 264 p.

Rodrigues, G. M.; Borges, M. S.; Virginio, J. da S.; Vergnano, C. G. Políticas públicas para o desenvolvimento rural: redes, formuladores, arenas e modalidades. Latin American Journal of Development, Curitiba, v.3, n.4, p. 1716-1734, jul./ago. 2021.

Singer, P. Introdução à economia solidária. São Paulo, SP: Perseu Abramo, 2002.

Soares, C. L. B. Moeda Social: uma análise interdisciplinar de suas potencialidades no Brasil contemporâneo. Tese 2006. Centro de Filosofia e Ciências Humanas da Universidade Federal de Santa Catarina.

Veiga, J. E. da et al. O Brasil rural precisa de uma estratégia de desenvolvimento. Texto para discussão n. 1. Brasília, MDA/NEAD, 2001. 